\title{
Liderança do diretor, clima escolar e desempenho dos alunos: qual a relação?
}

Ana Cristina Prado de Oliveira a Andrea Paula Souza Waldhelm ${ }^{\text {b }}$

\section{Resumo}

Utilizando-se dos dados da Prova Brasil-2013, o estudo, de natureza quantitativa, tem como proposta verificar a possível relação existente entre a liderança do diretor e o clima escolar (capturados pela percepção dos professores) com o desempenho dos alunos das escolas municipais e estaduais do Estado do Rio de Janeiro. Toma-se, como referencial teórico, os estudos sobre eficácia escolar, especialmente Sammons e Alves e Franco. O trabalho envolveu uma análise descritiva dos dados, a criação dos Índices Médios de Liderança e Colaboração Docente (IMLD e IMCE) e, por fim, uma regressão linear buscando relacionar os índices criados ao desempenho dos alunos do $5^{\circ}$ ano, mensurado pela média em Matemática. Foi possível verificar que, quando controlado o nível socioeconômico dos alunos, fatores escolares como a liderança do diretor e o clima escolar podem impactar positivamente os resultados dos alunos.

Palavras-chave: Gestão escolar. Liderança. Clima escolar. Eficácia da escola.

\section{Introdução}

Este trabalho propõe uma reflexão sobre a função de liderança do diretor escolar e as relações na escola, considerando a relevância destes fatores para o bom funcionamento das funções acadêmicas nas unidades de ensino, como tem sido apontado pelos estudos sobre as escolas eficazes (BRANDÃO; WALDHELM; FELIPE, 2008; MEDEIROS, 2007; FRANCO et al., 2007; BROOKE; SOARES 2008; entre outros). Paes de Carvalho et al. (2012) estudaram a influência da liderança do diretor junto ao corpo docente sobre os resultados escolares dos alunos. A análise das autoras confirmou o impacto estatisticamente significativo da liderança do diretor percebida pelos professores e das condições de trabalho

\footnotetext{
a Pontifícia Universidade Católica do Rio de Janeiro - Puc-Rio. Rio de Janeiro, Rio de Janeiro, Brasil.

b Faculdade de Filosofia, Ciências e Letras de Macaé. Macaé, Rio de Janeiro, Brasil. 
dos docentes (tipo de vínculo profissional com a escola) nos resultados de Matemática do $5^{\circ}$ ano do Ensino Fundamental no universo pesquisado (Região Metropolitana do Rio de Janeiro). O presente estudo pretende ampliar esta análise, considerando as escolas de todo o estado do Rio de Janeiro que atendem ao $5^{\circ}$ ano do Ensino Fundamental e que participaram da edição 2013 da Prova Brasil. Utilizando-se de uma análise multinível, o objetivo do estudo é capturar a percepção dos professores sobre a liderança, o diretor e a colaboração docente (como manifestação do clima escolar) e verificar como esta percepção, traduzida em índices, se associa ao desempenho de seus alunos nos testes de matemática da Prova Brasil de 2013.

Como corpus de pesquisa são utilizados os questionários contextuais aplicados aos diretores, professores e alunos do $5^{\circ}$ ano do Ensino Fundamental, cujas turmas participaram da edição de 2013 da Prova Brasil. Selecionamos trabalhar com os resultados das escolas municipais e estaduais, já que, a partir de levantamento prévio, detectamos que, no Estado do Rio de Janeiro, tanto a rede municipal quanto a rede estadual atendem ao primeiro segmento do Ensino Fundamental. É importante destacar que a predominância de atendimento ao $5^{\circ}$ ano, entre as escolas que participaram da Prova Brasil 2013, é das redes municipais ${ }^{1}$.

O presente artigo, fruto de uma pesquisa mais ampla ${ }^{2}$, traz como questões norteadoras:

1. Quem são os diretores das escolas municipais e estaduais do Estado do Rio de Janeiro?

2. Qual é a percepção dos professores do $5^{\circ}$ ano sobre o perfil de liderança dos diretores e sobre o clima escolar?

3. Como (e se) estas percepções se associam ao desempenho acadêmico dos alunos expressos nos testes de matemática da Prova Brasil 2013?

O texto está organizado em sete seções, incluindo esta introdução. Na segunda seção, apresentamos os referenciais teóricos que têm norteado a pesquisa, abordando a temática da qualidade educacional e avaliações em larga escala

\footnotetext{
Em 2013, das 2.248 unidades de ensino com dados disponibilizados da Prova Brasil para o $5^{\circ}$ ano do Ensino Fundamental do Estado do Rio de Janeiro (excluindo-se a rede de escolas federais), 150 pertenciam à rede estadual de ensino e 2.089 eram da rede municipal.

2 Referimo-nos à Pesquisa "Gestão e Qualidade do Ensino na Educação Básica" desenvolvida pelo GESQ Grupo de Estudo Gestão e Qualidade da Educação, PUC-Rio, sob a coordenação da Prof. Dra. Cynthia Paes de Carvalho. A pesquisa contou com o apoio da FAPERJ.
} 
no Brasil, e o papel da gestão da escola neste cenário. Na terceira seção, destacamos os caminhos metodológicos da pesquisa, inclusive a delimitação de nossa amostra. A quarta seção apresenta algumas características que traçam o perfil dos diretores das escolas do Estado do Rio de Janeiro que atendem ao $5^{\circ}$ ano, avaliadas na Prova Brasil 2013. Nas duas seções seguintes, tratamos sobre a liderança do diretor e o clima escolar/colaboração docente, índices criados a partir das respostas dadas pelos professores das escolas analisadas, e apresentamos o modelo estatístico que buscou relacionar os índices criados com o desempenho dos alunos do $5^{\circ}$ ano na Prova Brasil 2013. Finalmente, a sétima seção traz algumas conclusões do estudo e aponta encaminhamentos para os próximos passos da pesquisa.

\section{A Avaliação da Qualidade do Ensino e a Gestão Escolar}

\subsection{Avaliação como Medida da Qualidade}

Qualidade educacional é um termo polissêmico, podendo adotar diferentes definições dependendo do contexto em que é empregado. No que diz respeito à garantia do direito social à educação, a Constituição Federal de 1988, Art. 206, inciso VII, apresenta como um dos princípios basilares da educação nacional "a garantia de padrão de qualidade" (BRASIL, 1988).

Desenvolvendo um levantamento histórico, Oliveira e Araujo (2005) apontam três distintos significados que a expressão qualidade da educação assumiu ao longo da história da educação no Brasil: acesso à escola, fluxo e desempenho escolares. As políticas educacionais refletem estas associações, definindo a agenda de prioridades para as redes de ensino e o papel esperado dos gestores e agentes educacionais.

Na América Latina, a adoção das avaliações em larga escala para aferição do rendimento escolar tem sido identificada desde o início da década de 1990 do século passado. No Brasil, a criação de um Sistema de Avaliação da Educação Básica (SAEB) data do ano de 1990. A publicação dos resultados do SAEB, em 1997, favoreceu os estudos de eficácia, eficiência e equidade da educação brasileira. De acordo com Albernaz, Ferreira e Franco (2002, p. 03) "a disponibilização dos microdados do SAEB tornou possível, pela primeira vez no Brasil, a investigação dos determinantes de uma medida de desempenho escolar baseada em rendimentos de alunos em testes padronizados de conhecimento". 
Em 2005, o SAEB passou por uma reestruturação, passando a ser composto por duas avaliações: Avaliação Nacional da Educação Básica (ANEB) e Avaliação Nacional do Rendimento Escolar (Anresc), conhecida como Prova Brasil ${ }^{3}$. Desde 2013, o SAEB passou a ser composto por três avaliações: a ANEB, a Anresc e a ANA (Avaliação Nacional da Alfabetização) ${ }^{4}$.

Os questionários socioeconômicos que acompanham cada edição da aplicação da Prova Brasil:

[...] servem como instrumentos de coleta de informações sobre aspectos da vida escolar, do nível socioeconômico, capital social e cultural dos alunos. Professores de português e matemática das séries avaliadas e os diretores das escolas, também são convidados a responder questionários que possibilitam conhecer a formação profissional, práticas pedagógicas, nível socioeconômico e cultural, estilos de liderança e formas de gestão. Os questionários destinados aos professores e diretores são entregues pelos aplicadores antes da realização do teste e devem ser recolhidos ao final da prova ${ }^{5}$.

Assim, de acordo com Albernaz, Ferreira e Franco (2002), outras categorias podem, por conseguinte, ser incluídas nas análises, como as características dos discentes, de suas famílias, dos colegas da unidade de ensino onde estudam e dos docentes.

Dessa maneira, é possível verificar que a avaliação tem assumido um papel central, tanto na formulação quanto na implementação das políticas públicas na área educacional (BARRETO, 2001).

\subsection{A Gestão Escolar}

Em relação à instituição escolar, sabemos hoje que, entre os fatores intraescolares que podem influenciar positivamente a aprendizagem dos alunos, está a gestão da escola (SAMMONS, 2008; ALVES; FRANCO, 2008). Soares (2007, p. 153), a partir da proposição de um modelo conceitual para abordar o processo de aprendizagem em uma perspectiva multidisciplinar, considera que "dentro da escola

BRASIL. Ministério da Educação. Portaria Ministerial n 931, de 21 de março de 2005. [Institui o Sistema de Avaliação da Educação Básica - SAEB]. Diário Oficial da União, 22 mar. 2005, Seção 1, p. 17. Ministério da Educação. Portaria n 482, de 7 de junho de 2013. Dispõe sobre o Sistema de Avaliação da Educação Básica - SAEB. Diário Oficial da União, 10 jun. 2013, Seção 1, p. 17

5 Informação disponível no site do INEP: http://provabrasil.inep.gov.br/questionarios-socioeconomicos. Acesso em 18 de novembro de 2012 
há dois importantes processos que interagem para a produção do desempenho dos alunos: a gestão escolar e o ensino". De acordo com o autor, a gestão da escola, liderada pelo (a) diretor (a), compreende as tarefas relativas à garantia do funcionamento da escola no que se refere à rotina de funcionamento "de forma que os recursos nela existentes possam ser usados para atender às necessidades de aprendizagem dos alunos" (SOARES, 2007, p. 153). As diferenças encontradas nos resultados positivos dos alunos, que poderiam se relacionar ao trabalho da gestão da escola, geralmente estão vinculadas ao cumprimento das tarefas descritas acima, conciliando a manutenção de um ambiente propício para a aprendizagem e um trabalho coletivo de visão e metas compartilhadas entre a equipe.

Atualmente, alguns estudos têm buscado identificar perfis de liderança e características relacionadas à gestão pedagógica em escolas eficazes, como o trabalho de Polon (2009). Paes de Carvalho e Canedo (2008) também abordaram os diferentes perfis de gestores em estudo sobre escolas de prestígio no município do Rio de Janeiro. Inspiradas em Cousin (1998), as autoras discutem "os diferentes estilos de gestão escolar em termos dos principais fatores que os configuram: o contexto, o modelo de gestão e a coesão/mobilização dos agentes escolares, em particular o corpo docente" (PAES DE CARVALHO; CANEDO, 2008, p. 04).

O trabalho ora apresentado propõe uma discussão sobre as relações entre a liderança do diretor e o clima escolar (percebidos pelos professores) e os resultados dos alunos. Um recente levantamento bibliográfico (OLIVEIRA, 2015) apresentou algumas pesquisas nacionais e internacionais que se dedicaram ao estudo sobre as relações entre diretores e professores no contexto escolar, em alguns casos analisando os reflexos para os resultados de aprendizagem dos alunos. A autora conclui sua análise (que envolveu 42 artigos publicados entre 2010 e 2014) apontando a demanda, especialmente no contexto nacional, por estudos que articulem a reflexão sobre a gestão, a liderança e o clima escolar, uma vez que estes tendem a ser analisados nas pesquisas separadamente. Conceitualmente, os estudos de Rodney Ogawa e Steven Bossert propõem esta articulação a partir de dois conceitos importantes: liderança escolar como qualidade organizacional e clima escolar. Partindo dos estudos sobre as teorias das organizações, Ogawa e Bossert (1995) discutem a compreensão sobre a liderança nas perspectivas da teoria técnico-racional e da teoria institucional das organizações. Na perspectiva técnico-racional, considerada pelos autores como a visão dominante nos estudos sobre a liderança escolar, os líderes "operam dentro de culturas organizacionais e afetam a interpretação dos outros participantes sobre os eventos organizacionais, assim como influenciam a maneira como estes se comportam" (OGAWA; BOSSERT, 1995, p. 229, grifo dos autores, nossa tradução). Já na concepção institucional, a liderança é uma qualidade sistêmica das organizações, um fenômeno cultural, e "não está confinada a certos 
papéis nas organizações" (op. cit., p. 238). A compreensão da liderança escolar, como uma qualidade organizacional, implica, de acordo com os autores, em se compreender os microcontextos escolares, as relações que se constroem na escola. $\mathrm{E}$, mais importante (considerando o enfoque deste trabalho), os autores apontam que os professores estabelecem suas estratégias de ensino a partir das contingências que encontram no nível técnico das organizações escolares.

Nesta perspectiva e considerando a relevância do tema para a pesquisa que pretende compreender os processos escolares, assim como fomentar a discussão na viabilização de políticas educacionais, este trabalho propõe um olhar sobre a liderança do diretor e o clima escolar a partir do que pensam os professores do $5^{\circ}$ ano e dos resultados dos seus alunos.

\section{Metodologia e Dados}

Para a realização deste trabalho, utilizamos os questionários contextuais válidos respondidos por professores, diretores e alunos do $5^{\circ}$ ano do Ensino Fundamental, conforme já relatado nas seções anteriores. Além disso, optamos por trabalhar com os dados sobre o desempenho médio em Matemática do $5^{\circ}$ ano das escolas públicas estaduais e municipais do Estado do Rio de Janeiro. É oportuno registrar que a escolha pelo componente curricular se deve ao caráter escolar desta área de conhecimento, conforme apontam Rutter et al. (2008):

[...] a escolha das disciplinas escolares [cujos resultados de aprendizagem serão analisados] pode influenciar os resultados [da pesquisa]. Consequentemente, os estudos do IEA - International Educational Achievement Survey (Postlethwaite, 1975; Coleman, 1975), o Project Talent americano (Shaycoft, 1967) e a pesquisa britânica (Brimer et al., 1977) indicaram que disciplinas como, por exemplo, Matemática ou Ciências, que geralmente são aprendidas principalmente na escola, mostram maiores diferenças [de resultados] entre escolas do que a leitura, que pode ser aprendida em parte em casa com a ajuda dos pais; ou outras, como Literatura Inglesa ou Estudos Sociais, em que a aprendizagem dos alunos através da televisão ou de livros disponíveis em casa, e também em conversas com a família, provavelmente terá influência (op. cit., p.145-146).

$\mathrm{O}$ tratamento dos dados foi desenvolvido em várias etapas. Inicialmente, analisamos os dados dos questionários dos 2.248 diretores, traçando seu perfil quanto às características sociodemográficas, formação e experiência profissional e também aos aspectos relacionados aos processos de gestão e condições institucionais para o seu trabalho. 
Num segundo momento, analisamos os dados da base dos docentes respondidos por 6.433 professores do $5^{\circ}$ ano do Ensino Fundamental das escolas do Estado do Rio de Janeiro avaliadas na Prova Brasil de 2013. Desenvolvemos um estudo acerca da percepção que este grupo tem em relação à liderança do diretor e ao clima escolar/colaboração docente nas instituições de ensino onde atuam. Nesse sentido, utilizamos um bloco de questões ${ }^{6}$ indicando a escala de frequência em que os professores percebiam situações relacionadas à liderança do diretor e ao clima escolar. O procedimento estatístico de análise fatorial permitiu que as respostas dos professores para as questões levantadas se sintetizassem em dois índices, que nomeamos de Índice de Liderança do Diretor e Índice de Clima Escolar/Colaboração Docente. As cargas fatoriais de cada item do questionário indica a correlação entre este item e o índice criado (quanto maior o valor absoluto da carga fatorial, mais importante é aquele item na interpretação da análise fatorial). Para demonstrar a validade dos índices criados, seus itens e suas respectivas cargas fatoriais são apresentados nos Quadros 1 e 2, seguidos de sua medida de adequação da amostra (KMO) e de confiabilidade (Alpha de Cronbach).

Quadro 1. Cargas fatoriais das variáveis relativas à liderança do diretor.

\begin{tabular}{|l|c|}
\hline \multicolumn{2}{|c|}{ Índice de liderança do diretor } \\
\hline Variável & Carga Fatorial \\
\hline $\begin{array}{l}\text { O(A) diretor(a) discute metas educacionais com os professores nas } \\
\text { reuniões. }\end{array}$ & 0,726 \\
\hline $\begin{array}{l}\text { O(A) diretor(a) e os professores procuram assegurar que as questões de } \\
\text { qualidade de ensino sejam uma responsabilidade coletiva. }\end{array}$ & 0,751 \\
\hline $\begin{array}{l}\text { O(A) diretor(a) informa os professores sobre as possibilidades de } \\
\text { aperfeiçoamento profissional. }\end{array}$ & 0,743 \\
\hline $\begin{array}{l}\text { O(A) diretor(a) dá atenção especial a aspectos relacionados com a } \\
\text { aprendizagem dos alunos. }\end{array}$ & 0,837 \\
\hline $\begin{array}{l}\text { O(A) diretor(a) dá atenção especial a aspectos relacionados com as } \\
\text { normas administrativas. }\end{array}$ & 0,731 \\
\hline $\begin{array}{l}\text { O(A) diretor(a) dá atenção especial a aspectos relacionados com a } \\
\text { manutenção da escola. }\end{array}$ & 0,765 \\
\hline O(A) diretor(a) me anima e me motiva para o trabalho. & 0,847 \\
\hline O(A) diretor(a) estimula as atividades inovadoras. & 0,828 \\
\hline Sinto-me respeitado(a) pelo(a) diretor(a). & 0,761 \\
\hline Tenho confiança no(a) diretor(a) como profissional. & 0,802 \\
\hline
\end{tabular}

Extraction Method: Principal Component Analysis;

Variância explicada: 59,92\%; KMO: 0.924; Alfa de Cronbach: 0,936.

Fonte: Elaboração das autoras, com base nos microdados da Prova Brasil 2013, jul. /2015.

${ }_{6}$ Prova Brasil 2013, Questionário dos Professores, questões 53 a 67. 
Quadro 2. Cargas fatoriais das variáveis relativas ao clima escolar/colaboração docente.

\begin{tabular}{|l|c|}
\hline \multicolumn{2}{|c|}{ Índice de clima escolar/colaboração docente } \\
\hline Variável & Carga Fatorial \\
\hline Participou do planejamento do currículo escolar ou parte dele. & 0,561 \\
\hline Trocou materiais didáticos com seus colegas. & 0,669 \\
\hline $\begin{array}{l}\text { Participou de reuniões com colegas que trabalham com a mesma série } \\
\text { (ano) para a(o) qual leciona. }\end{array}$ & 0,747 \\
\hline $\begin{array}{l}\text { Participou em discussões sobre o desenvolvimento da aprendizagem de } \\
\text { determinados alunos. }\end{array}$ & 0,764 \\
\hline $\begin{array}{l}\text { Envolveu-se em atividades conjuntas com diferentes professores (por } \\
\text { exemplo, projetos interdisciplinares). }\end{array}$ & 0,711 \\
\hline
\end{tabular}

Extraction Method: Principal Component Analysis; Variância explicada: 59,92\%; KMO: 0.924; Alfa de Cronbach: 0,746.

Fonte: Elaboração das autoras, com base nos microdados da Prova Brasil 2013, jul. /2015.

Uma vez comprovada a validade e a confiabilidade dos índices criados, que nos possibilitaram uma medida sintética das percepções dos professores sobre os dois temas, iniciamos o estudo das relações propostas a partir da criação de um modelo estatístico para este fim. Assim, num terceiro momento, utilizamos o indicador de nível socioeconômico das escolas de educação básica (Inse), organizado pelo Inep, na Diretoria de Avaliação da Educação Básica, para analisar as características socioeconômicas das unidades de ensino. Optamos por fazer uso desse indicador em consonância com a estreita relação entre escola e sociedade, (COLEMAN, et al., 1966; BOURDIEU, 2004; BROOKE, 2008; entre outros), evidenciada por fatores extraescolares condicionantes da aprendizagem ${ }^{7}$. De acordo com o Instituto, o Inse foi construído

a partir das respostas dos estudantes aos questionários contextuais das duas avaliações do Saeb (Aneb e Prova Brasil) e do Enem. As questões utilizadas dizem respeito à renda familiar, à posse de bens e contratação de serviços de empregados domésticos pela família dos estudantes e ao nível de escolaridade de seus pais ou responsáveis. O universo de referência do Inse, por sua vez, inclui somente os dados de estudantes que responderam a mais de três questões (BRASIL, 2015, p. 6).

Na construção do indicador, as questões selecionadas foram tratadas pela Teoria de Resposta ao Item (TRI). E, a partir do modelo, uma medida individual foi

\footnotetext{
INEP. Microdados da Prova Brasil. 2013. Nota Técnica. Indicador de Nível Socioeconômico das Escolas de Educação Básica. Acesso: 30 de jul. 2015. Para mais informações sobre a construção do indicador, ver a íntegra do documento.
} 
organizada no âmbito do estudante, apresentada numa escala contínua, com média igual a 50 e desvio padrão igual a 10 . Por fim, sete níveis ordinais foram organizados e classificados, sintetizando o padrão de vida dos alunos, sendo o Nível I o mais baixo e o nível VII o mais alto (op. cit., p. 8-9). Assim, a partir de 2013, o INEP passou a apresentar, juntamente com os dados disponibilizados pela Prova Brasil, uma variável classificando a escola em um dos sete grupos.

Para operacionalizar este indicador em nosso estudo, tomamos como referência a porcentagem de alunos classificados nos níveis 5,6 e 7 (em média) que as escolas de cada grupo apresentavam. Dessa maneira, uma escola classificada no Grupo 1, tem, em média, apenas $0,4 \%$ de seus alunos apresentando um Inse alto, como pode ser visto no Quadro 3, mais a frente.

Por fim, ajustamos um modelo de regressão linear para verificar se os índices criados relacionados à gestão escolar e à liderança do diretor têm algum impacto no desempenho médio das escolas.

\section{Quem são os Diretores das Escolas Municipais e Estaduais no Estado do Rio de Janeiro?}

Nessa seção, apresentamos uma breve caracterização dos diretores das escolas municipais e estaduais do Estado do Rio de Janeiro, que atendem ao $5^{\circ}$ ano e participaram da edição de 2013 da Prova Brasil.

Considerando as respostas válidas, encontramos $91,0 \%$ de diretores do sexo feminino e $9,0 \%$ de diretores do sexo masculino. Com relação à faixa etária, a

Quadro 3. Descrição dos grupos de escolas.

\begin{tabular}{|l|c|}
\hline \multicolumn{2}{|c|}{ Inse dos alunos } \\
\hline Grupo de escolas & Porcentagem de alunos com Inse a partir do nível V \\
\hline Grupo 1 & $0,4 \%$ \\
\hline Grupo 2 & $1,3 \%$ \\
\hline Grupo 3 & $3,4 \%$ \\
\hline Grupo 4 & $9,0 \%$ \\
\hline Grupo 5 & $21,5 \%$ \\
\hline Grupo 6 & $50,6 \%$ \\
\hline Grupo 7 & $86 \%$ \\
\hline
\end{tabular}

Fonte: Elaboração das autoras, com base no Inse dos alunos disponibilizado pelo INEP. Jul./2015 
maioria (77,9\%) encontra-se com mais de 40 anos. Entre os respondentes, 54,7\% dos diretores se declararam brancos, $31,4 \%$ pardos, $1,8 \%$ pretos, $1,1 \%$ amarelos e $0,4 \%$ indígenas.

Entre os diretores analisados neste trabalho, o maior grupo (52,9\%) recebe entre $\mathrm{R} \$ 2.713,00$ e R \$ 6.780,00 como salário. Sobre este valor, cabe observar a diferença (a mais) em relação ao salário médio dos diretores das escolas que atendiam ao $5^{\circ}$ ano do Ensino Fundamental em 2009: de acordo com Paes de Carvalho et al. (2012, op. cit.) a maioria deles recebia entre $\mathrm{R} \$ 1.164,00$ e $\mathrm{R} \$ 2.325,00$. O mesmo foi verificado em relação ao ano de 2011, quando a média salarial dos diretores variou entre $R \$ 2.725,01$ e $R \$ 5.450,00^{8}$.

Analisando a formação acadêmica dos diretores das escolas selecionadas nesta pesquisa, encontramos que $93,6 \%$ possuem o nível superior de ensino, sendo destes $48,8 \%$ na área de Pedagogia e Curso Normal Superior, 36,5\% em Licenciaturas e 8,3\% em outras áreas, o que aponta a predominância da área educacional na formação destes diretores.

Com relação aos dados referentes à experiência do diretor, $91,9 \%$ declararam possuir mais de 10 anos de trabalho na área educacional, porém, apenas $28,9 \%$ exercem o cargo de direção há mais de 10 anos.

Nas escolas selecionadas nesta pesquisa, $81,9 \%$ dos diretores estão no cargo naquela unidade há menos de dez anos. Ainda sobre este aspecto, relevante na gestão escolar, vale destacar que $44,6 \%$ dos diretores pesquisados estão no cargo há menos de dois anos.

\section{Liderança do Diretor e Clima Escolar/Colaboração Docente: as Percepções dos Professores}

Os índices descritos na seção 3 deste trabalho foram construídos a partir da análise fatorial, com as respostas dadas pelos professores de $5^{\circ}$ ano cujas unidades de ensino participaram da Prova Brasil em 2013, no Estado do Rio de Janeiro. Sobre a relação entre as variáveis que compõem os fatores e os nomes dos índices criados, vale ressaltar que a escolha se baseou na literatura sobre liderança e clima escolar e na limitação dos itens disponíveis. Assim, no que se refere ao Índice de Liderança do Diretor, temos questões que abrangem as relações pessoais entre professores e diretores e outras que tratam das iniciativas do diretor relacionadas ao trabalho pedagógico ou administrativo

8 Conforme os dados disponibilizados pela edição da Prova Brasil 2011. 
da escola. Neste momento e com estes dados, estas variáveis (que poderiam indicar diferentes perfis de liderança do diretor) se agruparam em um mesmo fator, possivelmente indicando que as respostas do grupo analisado tendem a aproximar características relacionais, pedagógicas e administrativas ao analisar a liderança do diretor. Contudo, cabe ressaltar a limitação destes itens que não abordam todas as dimensões de liderança desempenhadas pelo diretor, mas que possibilitaram criar este Índice que propõe uma medida da percepção do professor sobre a liderança do diretor de uma forma ampla, sem especificar as possíveis tendências desta liderança.

Quanto ao Índice do Clima Escolar, ressaltamos que as variáveis que o compõem não contemplam todos os elementos que constituem o clima de uma escola. Neste caso, o questionário contextual da Prova Brasil traz outros itens relacionados à violência e à disciplina, porém fogem ao escopo deste trabalho. Interessa-nos conhecer qual é a percepção dos professores sobre as relações estabelecidas entre os educadores, com foco na melhoria do trabalho acadêmico. Assim, as variáveis que compõem este índice trazem algumas pistas sobre a coesão e a colaboração entre a equipe, elementos indicadores do clima escolar e geralmente relacionados ao trabalho do diretor, mas não esgotam o tema.

Os dois Índices criados foram então agrupados pela unidade escola, obtendo o Índice Médio para cada instituição de ensino. Nesta seção, passamos a descrever como se comportam o Índice Médio de Liderança do Diretor (IMLD) e o Índice Médio de Clima Escolar/Colaboração Docente (IMCE). No que se refere aos dois índices, quanto maior e positivo o índice, maior o valor médio da percepção dos professores sobre a Liderança do Diretor e o Clima Escolar nas escolas.

O Quadro 4 apresenta a variação dos valores agregados dos índices entre as escolas analisadas, ou seja, o menor e o maior valor encontrados e sua média, assim como o seu desvio padrão.

Quadro 4. Índice Médio da Liderança do diretor e Índice Médio de Clima Escolar/Colaboração Docente no Estado do Rio de Janeiro.

\begin{tabular}{|l|c|c|c|c|}
\hline & Mínimo & Máximo & Média & Desvio Padrão \\
\hline IMLD & $-2,92$ & 2,00 & 0,0642 & 0,83338 \\
\hline IMCE & $-3,35$ & 1,90 & $-0,0802$ & 0,87035 \\
\hline
\end{tabular}

Fonte: Elaboração das autoras, com base nos microdados da Prova Brasil 2013, julho/2015. 


\section{Liderança, Clima Escolar e Desempenho}

A seguir, passamos a descrever a análise multivariada desenvolvida com vistas a identificar o impacto dos índices criados no desempenho dos alunos de $5^{\circ}$ ano. Para tanto, ajustamos um modelo de regressão linear, cuja variável dependente foi a média da proficiência em Matemática dos alunos do $5^{\circ}$ ano, e a variável de controle foi o Inse médio das escolas, tomando como referência a porcentagem de alunos com Inse alto (a partir do nível V), conforme descrito em seção anterior.

A equação da regressão tomada como referência para a análise seguiu a fórmula:

Nota_Média_Prova Brasil $=\beta 0+\beta 1($ Inse $)+\beta 2($ IMLD $)+\beta 3($ IMCE $)+e$

Estatisticamente, esta fórmula representa os fatores que interferem na variação de resultados das escolas na Prova Brasil 2013 (média dos alunos do $5^{\circ}$ ano em Matemática): $\beta 0$ indica a nota média na Prova Brasil (quando Inse, IMLD e IMDE são iguais zero); $\beta 1$ é o indicador de Inse da escola, utilizado como controle da equação; $\beta 2$ é o Índice de Liderança do Diretor (média por escola); $\beta 3$ é o Índice de Clima Escolar/Colaboração Docente; "e" é o erro aleatório, ou seja, representa o resultado médio do aluno na Prova Brasil que não pode ser atribuído nem ao Inse, nem ao IMLD e nem ao IMCE. Os Quadros 5 e 6 apresentam a definição e a estatística descritiva (variação dos valores entre as escolas) destas variáveis.

Quadro 5. Variáveis utilizadas no modelo.

\begin{tabular}{|c|c|c|}
\hline Variável & $\begin{array}{l}\text { Tipo de } \\
\text { variável }\end{array}$ & Descrição \\
\hline \multicolumn{3}{|l|}{ Dependente } \\
\hline $\begin{array}{l}\text { Nota_Média_ } \\
\text { Prova_Brasil }\end{array}$ & Contínua & $\begin{array}{l}\text { Proficiência média em Matemática dos alunos do } 5^{\circ} \text { ano } \\
\text { das escolas municipais e estaduais do Estado do Rio de } \\
\text { Janeiro na Prova Brasil, } 2013 .\end{array}$ \\
\hline \multicolumn{3}{|c|}{ Independentes } \\
\hline Inse & Contínua & $\begin{array}{l}\text { Nível socioeconômico - Percentual de alunos com Inse } \\
\text { alto (a partir do nível V). }\end{array}$ \\
\hline IMLD & Contínua & Índice médio de liderança do diretor (Q58 a Q67). \\
\hline IMCE & Contínua & $\begin{array}{l}\text { Índice médio de clima escolar/colaboração docente } \\
\text { (Q53 a Q57). }\end{array}$ \\
\hline
\end{tabular}

Fonte: Elaboração das autoras, com base nos microdados da Prova Brasil 2013, Julho/2015. 
Quadro 6. Estatística descritiva das variáveis utilizadas no modelo.

\begin{tabular}{|l|c|c|c|c|}
\hline Variável & Média & Desvio padrão & Mínimo & Máximo \\
\hline Nota_Média_Prova_Brasil & 212,49 & 20,28011 & 137,36 & 306,70 \\
\hline Inse & 16,61 & 7,73852 & 3,40 & 86,00 \\
\hline IMLD & 0,0642 & 0,83338 & $-2,92$ & 2,00 \\
\hline IMCE & $-0,0802$ & 0,87035 & $-3,35$ & 1,90 \\
\hline
\end{tabular}

Fonte: Elaboração das autoras, com base nos microdados da Prova Brasil 2013, Julho/2015.

Quadro 7. Coeficientes do modelo estimado.

\begin{tabular}{|l|c|c|}
\hline & Coeficiente $(\boldsymbol{\beta})$ & Significância \\
\hline Constante (Nota média Prova Brasil) & $* * * *$ & 0,000 \\
\hline Inse & 0,337 & 0,000 \\
\hline IMLD & 0,145 & 0,000 \\
\hline IMCE & 0,111 & 0,000 \\
\hline
\end{tabular}

$\mathrm{R}^{2}=0,159^{9}$

Fonte: Elaboração das autoras, com base nos microdados da Prova Brasil 2013, julho/2015.

Uma vez rodada a regressão linear, encontramos os coeficientes de associação apresentados no Quadro 7 acima.

Conforme mostra o Quadro 7, as variáveis que entraram no modelo apresentaram relação significativamente positiva (coeficientes com valor positivo e com significância menor do que 0,001 ) em relação ao resultado dos alunos do $5^{\circ}$ ano na avaliação de Matemática da Prova Brasil 2013. Nesse sentido, o nível socioeconômico dos alunos foi a variável que apresentou a maior relação positiva, em conformidade com os estudos acerca da relação escola e sociedade, mais especificamente no que tange às características socioeconômicas das famílias e às desigualdades educacionais.

As pesquisas em eficácia escolar apontam que, se o background familiar tem um peso importante na definição do desempenho acadêmico do aluno, alguns fatores intraescolares poderiam minimizar o efeito da origem social, promovendo a eficácia e a equidade na oferta educacional (BROOKE; SOARES, 2008; SAMMONS, 2008; FRANCO et al., 2007). Neste estudo, no modelo estimado descrito anteriormente, o IMLD apresentou relação positiva com o resultado dos alunos no teste de Matemática. De acordo com o modelo estimado, para cada aumento de 1 desvio padrão na variável IMLD, a média dos resultados de Matemática dos alunos do $5^{\circ}$

$9 R^{2}$ ajustado. 
ano aumenta 0,14 ponto (valor arredondado). Ou seja, escolas onde os professores apresentaram uma percepção mais positiva sobre a liderança do diretor, apresentaram melhores resultados nos testes de Matemática de seus alunos do $5^{\circ}$ ano.

Este resultado corrobora a atenção que tem sido dada ao campo da gestão e liderança nas escolas, considerada como importante fator de influência no resultado de aprendizagem dos alunos. Leithwood (2009) destaca, entre os fatores que influenciam os resultados dos estudantes (para além das práticas docentes), que "os líderes escolares también tienem un efecto sobre el aprendizaje de los estudiantes, pero su incidencia es más bien indirecta" (op. cit., p. 20). Considerando os recentes estudos na área, Leithwood destaca que, ainda que a liderança escolar somente explique entre $3,0 \%$ e 5,0\% da variância de aprendizagem dos alunos entre escolas, representa um quarto da variância total quando controladas as variáveis de origem dos alunos e analisados somente os fatores intraescolares (op. cit., p. 23).

O outro índice criado neste estudo buscou medir a percepção dos professores sobre o clima escolar e a colaboração docente, temas estritamente relacionados ao trabalho da gestão escolar e que estão entre os fatores-chave para que o diretor exerça um efeito positivo no rendimento dos alunos, conforme aponta Bonamino (2012, p. 125). Tais fatores envolvem a capacidade de compartilhar a autoridade com a equipe, o acompanhamento sistemático e pessoal das atividades escolares, a capacidade de identificação e articulação de metas e prioridades, o exercício de uma liderança pedagógica, entre outras.

Neste estudo, o IMCE também apresentou relação positiva, ainda que pequena, com o desempenho dos estudantes. De acordo com o modelo estimado, para cada aumento de 1 desvio padrão na variável IMCE, a média dos resultados de matemática dos alunos do $5^{\circ}$ ano aumenta 0,11 ponto (valor arredondado). Ou seja, escolas que apresentaram uma percepção mais positiva dos professores sobre o clima escolar, também apresentaram melhores resultados nos testes de Matemática de seus alunos do $5^{\circ}$ ano. Conforme lembram Brito e Costa (2010), a ideia de que a "atmosfera" ou o ambiente circundante percebido pelos indivíduos na escola exerce significativa influência sobre o comportamento e a qualidade do trabalho desenvolvido é um consenso nos estudos neste campo. Em pesquisa sobre a percepção dos professores acerca do prestígio e do clima escolar em escolas públicas do Rio de Janeiro, os autores apontam que 


\begin{abstract}
A literatura sobre clima escolar tem destacado a figura do gestor como um agente crucial na promoção de um clima favorável nas escolas, e os relatos dos professores colaboram para evidenciar a influência da gestão na construção desse bom clima de trabalho. Aspectos como gestão democrática, mobilização comunitária e fortalecimento da equipe parecem contribuir para promover o maior envolvimento dos professores nas atividades escolares, favorecendo o aprendizado escolar dos alunos (BRITO; COSTA, 2010, p. 506).
\end{abstract}

O modelo estimado explicou 15,9\% da variabilidade dos resultados dos alunos do $5^{\circ}$ ano do Ensino Fundamental em Matemática, no Estado do Rio de Janeiro. Dessa maneira, retomando nossa questão de pesquisa, percebemos a relação entre a liderança do diretor, o clima escolar e os resultados dos alunos, demonstrada através dos resultados apresentados. O modelo sugere que, controlado pelo Inse, a liderança do diretor e o clima escolar/colaboração docente (percebidos pelos professores) associam-se positivamente ao desempenho dos estudantes. O resultado nos permite inferir que, na amostra estudada, quanto melhor os professores percebem o trabalho de seu diretor e o clima de trabalho em sua escola, maiores são os resultados de seus alunos. Em recente pesquisa desenvolvida em escolas municipais do Rio de Janeiro, Oliveira (2015) encontrou que a variável utilizada para mensurar a percepção dos professores sobre o ambiente escolar associava-se positiva e significativamente com os resultados de aprendizagem dos alunos e com o nível de satisfação dos professores no trabalho. Poderíamos dizer que, entre as escolas estudadas, identificamos uma combinação entre reconhecimento da liderança e percepção de um clima organizacional escolar favorável ao trabalho docente com a melhoria dos resultados dos alunos nos testes de Matemática. Esta combinação de fatores atuando no interior da escola poderia compor o que Rutter e colegas (2008) chamaram de "efeito institucional". Ou seja, ainda que características do perfil de liderança do diretor ou determinadas tarefas que adote na condução da gestão da escola ou ainda características específicas do clima escolar atuem no nível de aprendizagem dos alunos, o "efeito combinado" destas especificidades (o ethos da escola) tem um poder de atuação mais poderoso.

\title{
7 Considerações Finais
}

A qualidade da educação nacional faz parte da agenda dos gestores atuais, por isso, inúmeras iniciativas têm sido observadas em prol da permanência bemsucedida dos estudantes no sistema educacional. As avaliações em larga escala, assim, podem ser consideradas bons instrumentos de monitoramento das políticas educacionais empreendidas pelos governos em nível federal, estadual e municipal. 
Neste estudo, procuramos identificar alguns fatores intraescolares relacionados à gestão escolar que podem impactar no desempenho em matemática de estudantes participantes da edição de 2013 da Prova Brasil, nas escolas estaduais e municipais do Estado do Rio de Janeiro. Nossa hipótese inicial nos levou à criação do IMLD e do IMCE a partir das respostas dos professores do $5^{\circ}$ ano ao questionário contextual da Prova Brasil 2013. O modelo estimado para captar a relação entre estes índices e o resultado acadêmico das escolas estaduais e municipais do estado do Rio de Janeiro demonstrou a relação significativamente positiva entre a liderança do diretor e o clima escolar (percebida pelos professores) e o resultado dos alunos nos testes de Matemática do $5^{\circ}$ ano.

Questões relacionadas à gestão/liderança da escola e ao clima acadêmico aparecem como importantes fatores associados ao efeito-escola. Entende-se por efeitoescola "o quanto um dado estabelecimento escolar, por suas políticas e práticas internas, acrescenta ao aprendizado do aluno" (BROOKE; SOARES, 2008, p. 10). Neste sentido, muitas discussões vêm sendo feitas sobre a medida adequada deste aprendizado. Brooke e Soares (2008, p. 222) consideram que

a medida do aprendizado exige o acompanhamento longitudinal dos alunos, com o registro de sua proficiência no ponto inicial de uma trajetória escolar e, depois, em outros pontos subsequentes. A diferença entre o desempenho do aluno nesses dois ou mais pontos é uma medida do seu aprendizado, e a média dos aprendizados é definida como o valor agregado da escola.

A título de esclarecimento, cabe aqui uma importante observação a fim de evitar incorrermos em um erro terminológico comum: a utilização do conceito efeito. No trabalho estatístico que propomos nesta pesquisa, ao tratarmos sobre a percepção dos professores acerca da liderança do diretor e do clima escolar investigamos uma possível relação destes fatores com o desempenho dos alunos. Não se pretendeu, neste estudo, verificar ou medir o efeito destes fatores sobre o desempenho dos alunos, uma vez que, para tanto, necessitaríamos desenvolver um estudo longitudinal para medir o efeito agregado pela escola à aprendizagem dos alunos, como descrito na citação acima.

Apesar de esta análise exploratória nos apresentar pistas interessantes que merecem ser aprofundadas, é importante considerar que seus resultados podem estar comprometidos pela possível imprecisão das variáveis que compõem o modelo. A medida dos índices (IMLD e IMCE) torna-se comprometida, tanto pela fragilidade dos itens que os compõem quanto pelo número de respondentes. 
Sobre este segundo agravante Soares et al. (2012, p. 55), em estudo a partir dos dados da Prova Brasil de 2005, 2007 e 2009, já assinalavam:

[...] os dados colhidos por meio dos questionários da Prova Brasil, aplicados a professores e diretores, permitem o cálculo dos fatores que exploramos aqui, mas não foram especificamente elaborados para tanto, além de apresentarem um alto índice de não resposta. Como resultado, temos medidas frágeis de construtos, tais como ambiente escolar, qualidade das instalações e outros.

O trabalho de análise e cruzamento de informações a partir da leitura dos dados disponibilizados pelo INEP tem proporcionado uma significativa ampliação no alcance das pesquisas educacionais. Nesse sentido, ressaltamos a importância dos documentos da Prova Brasil como instrumento para monitorar a qualidade da oferta educacional, bem como dar pistas para novos investimentos na área da educação. Ainda assim, algumas limitações acerca dos dados disponíveis são percebidas (como, por exemplo, as questões sobre a temática da liderança e do clima escolar poderiam ser melhor exploradas; os questionários são respondidos apenas pelos professores das séries testadas) e vem sendo debatidas, encorajando o desenvolvimento de novos surveys no campo.

Ainda que se considerem as limitações apontadas e a abrangência de um estudo exploratório, as análises apresentadas levantam importantes pistas sobre a construção das percepções docentes acerca da gestão escolar (liderança e clima escolar/colaboração docente) e sobre a possível relação entre estas e os resultados acadêmicos de seus alunos. Os resultados apontam a direção para novos estudos, envolvendo a análise das relações estudadas em outros contextos (outros Estados, regiões e para todo o país), assim como a ampliação da coleta de dados sobre a temática estudada, através da proposição de novos instrumentos de pesquisa e da continuidade da discussão sobre o tema. 


\title{
Principal's leadership, school climate and student achievement: what is the relationship?
}

\begin{abstract}
Using data from the Prova Brasil-2013, this quantitative study proposes to verify the possible relationship between the principal's leadership and the school climate (captured by the teachers 'perception) with the students' academic performance, in municipal and state schools of the State of Rio de Janeiro. Studies on school effectiveness are taken as a theoretical basis, especially Sammons and Alves and Franco. The work involved a descriptive analysis of the data, the creation of the indexes of leadership and teacher collaboration (IMLD and IMCE) and, finally, a linear regression trying to relate the indexes created with the performance of the 5th grade students, measured by the average in mathematics. We found that, after controlling the students'socioeconomic status, some school factors - as the principal's leadership and the school climate - can positively impact student's achievement.
\end{abstract}

Keywords: School management. Leadership. School climate. Effectiveness of school.

\section{Liderazgo del director, ambiente escolar y el logro del estudiante: ¿qué relación?}

\section{Resumen}

Utilizando los datos de la Prova Brasil-2013, el estudio, de naturaleza cuantitativa, se propone comprobar la posible relación entre el liderazgo del director y el clima escolar (capturados por la percepción de los profesores) con el rendimiento de los estudiantes de las escuelas municipales y estaduales del Estado de Río de Janeiro. Se toma como base teórica, los estudios sobre la eficacia escolar, especialmente Sammons y Alves y Franco. El trabajo involucró un análisis descriptivo de los datos, la creación de las tasas medias de liderazgo y colaboración de los maestros (IMLD y IMCE) y, por último, una regresión lineal tratando de relacionar los índices creados con el desempeño de los estudiantes del quinto año, medido por el promedio en matemáticas. Se encontró que, cuando se controla el nivel socioeconómico de los estudiantes, factores escolares como el liderazgo del director principal o el clima escolar pueden repercutir positivamente en el rendimiento estudiantil.

Palabras clave: Gestión escolar. Liderazgo. El clima escolar. Eficacia de la escuela 


\section{Referências}

ALBERNAZ, A.; FERREIRA, H. G. F.; FRANCO, C. Qualidade e equidade no ensino fundamental brasileiro. Pesquisa e Planejamento Econômico, v. 32, n. 3, p. 1-26, 2002.

ALVES, M. T. G.; FRANCO, C. A pesquisa em eficácia escolar no Brasil: evidências sobre o efeito das escolas e fatores associados à eficácia escolar. In: BROOKE, N.; SOARES, J. F. Pesquisa em eficácia escolar: origem e trajetórias. Belo Horizonte: Editora UFMG, 2008. p. 482-500.

BARRETO, E. S. S. A avaliação na educação básica entre dois modelos. Educação e Sociedade, v. 22, n. 75, p. 48-66, 2001. doi:10.1590/S0101-73302001000200005

BONAMINO, A. M. C. Características da gestão escolar promotoras de sucesso. In: POLON, T. L. P. et al. Gestão do currículo e gestão e liderança. Juiz de Fora: Editora do CAED, 2012. (Gestão e Avaliação da Educação Pública, 3). p. 117-32

BOURDIEU, P. Escritos de educação. Petrópolis: Vozes, 2004.

BRANDÃO, Z.; WALDHELM, A. P. S., FELIPE, L. H. L. Sites escolares: uma nova estratégia na construção da imagem de excelência das instituições de ensino? Boletim SOCED, n. 6, p. 1-21, 2008.

BRASIL. Congresso Nacional. Constituição da República Federativa do Brasil. Brasília, DF: Senado Federal, 1988.

. Ministério da Educação. Instituto Nacional de Estudos e Pesquisas Educacionais Anísio Teixeira - INEP. Nota técnica: Indicador de Nível Socioeconômico das Escolas de Educação Básica (Inse) participantes da Avaliação Nacional da Alfabetização (ANA). Brasília, DF: INEP, 2015. Disponível em: $<$ http://download.inep.gov.br/educacao_basica/saeb/ana/ resultados/2014/nota_tecnica_inse.pdf $>$. Acesso em: 30 mai 2015.

BRITO, M. S. T.; COSTA, M. Práticas e percepções docentes e suas relações com o prestígio e clima escolar das escolas públicas do município do Rio de Janeiro. Revista Brasileira de Educação, v. 15, n. 45, p. 500-10, set./dez. 2010. doi:10.1590/S1413-24782010000300008

BROOKE, N.; SOARES, J. F. (Orgs.). Pesquisa em eficácia escolar: origem e trajetórias. Belo Horizonte: UFMG, 2008. 
COLEMAN, J. S. et al. Equality of educational opportunity. Washington, DC: US Department of Health, Education and Welfare, 1966.

FRANCO, C. et al. Qualidade e equidade em educação: reconsiderando o significado de "fatores intra-escolares". Ensaio, v. 15, n. 55, p. 277-98, abr./jun. 2007. doi:10.1590/S0104-40362007000200007

LEITHWOOD, K. ¿Cómo liderar nuestras escuelas? Aportes desde la investigación. Santiago: Salesianos Impresores, 2009.

MEDEIROS, V. G. Clima escolar: um estudo sociológico de uma instituição pública de excelência. 2007. 151 f. Dissertação (Mestrado em Educação Brasileira) - Departamento de Educação, Pontifícia Universidade Católica do Rio de Janeiro, Rio de Janeiro, 2007.

OGAWA, R. T.; BOSSERT, S. T. Leadership as an organizational quality. Educational Administration Quarterly, v. 31, n. 2, p. 224-43, maio 1995. doi:10.1177/0013161X95031002004

OLIVEIRA, A. C. P. As relações entre direção, liderança e clima escolar em escolas municipais do Rio de Janeiro. Rio de Janeiro, 2015. 283 f. Tese (Doutorado em Educação) - Coordenação de Pós-Graduação, Pontifícia Universidade Católica do Rio de Janeiro, 2015.

OLIVEIRA, R. P.; ARAUJO, G. C. Qualidade do ensino: uma nova dimensão da luta pelo direito à educação. Revista Brasileira de Educação, n. 28, p. 5-23, jan./abr, 2005. doi:10.1590/S1413-24782005000100002

PAES DE CARVALHO, C.; CANEDO, M. L. Estilos de gestão em escolas de prestígio na cidade do Rio de Janeiro. Boletim SOCED, v. 6, p. 1-30, 2008.

PAES DE CARVALHO, C.; WALDHELM, A. P. S.; ALVES, F. C. M.; KOSLINSKI, M. C. Gestão e desempenho escolar: um estudo nas redes municipais da região metropolitana do Rio de Janeiro a partir dos resultados da Prova Brasil 2009. In: CONGRESSO IBERO-AMERICANO DE POLÍTICA E ADMINISTRAÇÃO DA EDUCAÇÃO, 3., 2012, Zaragoza, Espanha, 2012. Cadernos ANPAE.

POLON, T. Identificação dos perfis de liderança e características relacionadas à gestão pedagógica eficaz nas escolas participantes do Projeto Geres: estudo longitudinal: geração escolar 2005: Polo Rio de Janeiro. 2009. Tese. 323 f. (Doutorado em Educação) - Coordenação de Pós-Graduação, Pontifícia Universidade Católica do Rio de Janeiro, 2009. 
RUTTER, M. et al. Introdução: estudos anteriores. In: BROOKE, N.; SOARES, J. F. (Orgs.). Pesquisa em eficácia escolar: origem e trajetórias. Belo Horizonte: Editora UFMG, 2008. p. 142-52.

SAMMONS, P. As características-chave das escolas eficazes. In: BROOKE, N.; SOARES, J. F. (Orgs.). Pesquisa em eficácia escolar: origem e trajetórias. Belo Horizonte: Editora UFMG, 2008. p. 335-82.

SOARES, J. F. Melhoria do desempenho cognitivo dos alunos do Ensino Fundamental. Cadernos de Pesquisa, v. 37, n. 130, p. 135-60, jan./abr. 2007. doi:10.1590/S0100-15742007000100007

SOARES, J. F. et al. Exclusão intraescolar nas escolas públicas brasileiras: um estudo com dados da prova Brasil 2005, 2007 e 2009. Brasília, DF: Unesco, 2012. (Série Debates ED, 4).

\section{Informações das autoras}

Ana Cristina Prado de Oliveira: Doutora em Educação pela PUC-Rio, Professora substituta no Departamento de Educação da UFRJ, Pós-Doutoranda no Departamento de Educação da PUC-Rio com o apoio do CNPq. Pesquisadora integrante do GESQ - Grupo de Estudo Gestão e Qualidade da Educação, PUC-Rio. Contato: ana.prado.oliveira@gmail.com

Andrea Paula Souza Waldhelm: Doutora em Educação pela PUC-Rio, Professora da Faculdade de Filosofia, Ciências e Letras de Macaé e orientadora educacional na Secretaria Municipal de Educação Macaé. Pesquisadora integrante do GESQ - Grupo de Estudo Gestão e Qualidade da Educação, PUC-Rio. Contato: pwaldhelm12@gmail.com 